\title{
Financial mechanisms of international relations in the era of global transformations and the digital revolution
}

\author{
Viktoriya Razletovskaia \\ MGIMO University, Prospect Vernadskogo, 76, 119454 Moscow, Russia
}

\begin{abstract}
Globalization, scientific and technological progress, and the digital revolution lead not only to a change in international relations, but also to the transformation of the financial component of their implementation. New challenges, such as neurotechnology, creating a new community of automated subjects, artificial intelligence, threatening mass unemployment, information in volumes impossible to perceive and process by human brain, consolidation of stratification and inequality, radical changes in human values and uniqueness, cyber threats to both individuals and society as a whole pose challenges that will require unprecedented international cooperation, supported by the development of financial mechanisms and instruments. Otherwise, there is a risk of a "digital divide" with serious consequences for stable growth around the world. The urgency and complexity of the problem is supported by the fact that the past world historical experience knows no such cooperation, as there were no appropriate conditions (changed not only the environment and factors, but also the range of threats that have not been so global). The article presents an analysis of the convergence of the development of international relations and financial instruments and technologies for their implementation based on the level of scientific and technological progress on the example of the stages of historical processes of globalization and the digital revolution. Given the identified trends in the development of financial instruments and technologies of international processes, the article shows that an important challenge for Russia is to establish its own foreign policy priorities and determine its place and role in the financial component of world politics. A new range of emerging financial instruments is shown, the application of which will be a key factor in the development of future public policies.
\end{abstract}

\section{Introduction}

International relations and their forms of organization and instruments, including financial ones, must correspond to the level of development of scientific and technological progress, in particular to the era of the digital revolution. Studies of international relations and mechanisms of their implementation are transformed from the classification of their types in terms of classical approaches in historical and social aspects, to the macro-sociological paradigm in the approach to their study, considering the sphere of transnational relations as a single international society (from I. Bentham, N. Machiavelli, T. Hobbes, E. Wallerstein, 
S. Hoffman, G. Kissinger, G. Morgenthau, R. Aron, J. Modelski to K. Wright, M. Kaplan, E. Haas, R. Cohain, D. Nai, D. Mitrani, K. Waltz, D. Easton, P. Tsygankova, etc.). Among the classical approaches to political realism, based on historical and social aspects, the commitment to an interdisciplinary approach, the desire to apply rigorous scientific methods and procedures and to increase the number of verifiable empirical data are common to modern studies of the classification of international relations of the modernist direction. If the controversy between modernists and political realists concerned mainly the methods of studying the classification of international relations, the representatives of transnationalism and theories of integration and interdependence, in turn, try to go beyond the prevailing intergovernmental and interethnic approach to classification. The diversity of participants, types of international relations and channels of interaction between them, the growth of transnational corporations displace states from the center of international communication, and contribute to the transformation of such communication from "international" to transnational, without state participation. Movements of neorealism and structuralism are developing, according to which the structural properties of the international system do not actually depend on any efforts of small and medium-sized states, as a result of the interaction of great powers and empires. New global revolutionary changes in scientific and technological progress and the growth rate of the digital economy have significant transformations in international relations. The estimate of the size of the digital economy (based on methodological approaches to accounting in different countries) varies from 4.5 to 15.5 percent of world GDP. In terms of value added in the information and communication technology (ICT) sector, the United States and China account for almost $40 \%$ of the world. However, in terms of GDP, the sector is the largest in the Chinese provinces of Taiwan, Ireland, and Malaysia. Global employment in the ICT sector increased from 34 million in 2010 to 39 million in 2015 , with computer services as a leader (38\%). The share of the ICT sector in total employment increased from $1.8 \%$ to $2 \%$ over the same period. Digital platforms are playing an increasingly important role in the global economy. In 2017, the total value of platform-based companies with a market capitalization of more than $\$ 100$ million exceeded an estimated \$ 7 trillion, which is $67 \%$ more than in 2015 . Some of global digital platforms have gained solid market positions in certain segments at the global level. For example, about $90 \%$ of the Internet search engine market belongs to Google. Facebook accounts for two-thirds of the global social media market and is the most popular social media platform in over $90 \%$ of countries. Almost $40 \%$ of the world's online retail sales are conducted through Amazon's network, and its subsidiary Amazon Web Services accounts for roughly the same share of the global cloud infrastructure services market. China's WeChat (owned by Tencent) has over a billion active users, and its payment system, along with Alipay (owned by Alibaba), covers almost the entire Chinese market for mobile payments. Alibaba accounts for an estimated $60 \%$ of the Chinese e-commerce market [UNCTAD, 2019]. The rapid consolidation of the dominance of these largest digital giants in the global marketplace is leading to highly uneven geographic development of the digital economy. For example, the United States and China account for $75 \%$ of all blockchain-related patents, $50 \%$ of global IT spending and over $75 \%$ of the global public cloud computing market, as well as $90 \%$ of the market capitalization of the world's 70 largest digital platforms. The share of Europe is $4 \%$, while Africa and Latin America together account for only $1 \%$. Seven super platforms Microsoft, followed by Apple, Amazon, Google, Facebook, Tencent, Alibaba - account for two-thirds of the total market value. Thus, the rest of the world, especially Africa and Latin America, lags far behind the United States and China in many digital technology developments. For example, in least developed countries only one of five people uses the Internet, compared with four of five in developed countries; Africa and Latin America together account for less than 5\% of the world's data centers [UNCTAD, 2019]. Thus, there is a need for systemic and integrated studies of the development trends of these processes in 
correlation with each other. The study of financial mechanisms for the implementation of international relations, as the most susceptible to transformation in the context of the digital revolution, becomes especially relevant. The objective is to determine the development trends of financial mechanisms and instruments of international relations from the level of development of scientific and technological progress.

\section{Methods}

The authors have analyzed and identified patterns of the development of international relations and the financial mechanisms of their implementation based on the level of development of scientific and technological progress and information technologies, using the example of two stages - globalization and the digital revolution. They determined types of financial instruments of international relations and the forms of their organizations. The article provides a traditional historical analysis in terms of information processing and the development of digital technologies (artificial intelligence and neurotechnologies) in correlation with the level of development and types of international relations and their financial mechanisms of implementation. The use of an interdisciplinary approach to the study of the history of international relations, and their implementation tools [R.O. Keohane et al, 1972], and systems analysis for the functioning and evolution of the system through the prism of the environment of the system of international relations [Easton D., 1965], as a set of factors that affect the global international system, imposing restrictions and coercions its development, allowed going beyond the classical methodology of the traditional history of diplomacy. The evolution of the financial mechanisms of international relations is shown as a change of systems.

\section{Results and Discussion}

During the period from globalization to the digital revolution, international relations and financial instruments for their implementation have significantly transformed and qualitatively changed. The authors tried to determine the relationship of international relations and financial mechanisms for their implementation to the level of information processing, development of scientific and technological progress and digitalization processes.

The prerequisites for the era of globalization is a new economic order, where all are united by money, empires, and religions [Yuval Noah Harari, 2019].

One of the main factors in the unification of mankind is the dramatic changes that have occurred in the processing and use of information and digital technologies:

1) the emergence of new globalization-contributing technologies (biochemistry, biophysics, digital technologies, cybernetics, a qualitatively new level and speed of information processing on the Internet, personal computers and gadgets);

2) the emergence of the main product - information;

3) the XX century - the century of tracking systems, communication and management, development of management and organization, international marketing;

4) world trade and the growth of transnational companies and empires require standardization and unification, the destruction of individuality;

5) global problems of mankind: climate, threat of nuclear war, etc.

The main challenges of this process are the organization and ordering of world chaos. Globalization is one of the stages in the development of cross-border capitalism aimed at expanding and searching for new markets, consolidating sustainable development and 
stimulating consumption. The goals of these processes are aimed at serving the interests of the world's economic and financial elites.

We shall consider the way these processes have affected international relations and financial mechanisms and instruments for their implementation. First, the struggle for land, energy, natural and human resources of the industrial revolution was replaced by the conquest of markets, including international and technology, through international trade, international law, international organizations and regulation [Harari Yu.N., 2011]. The struggle for information, control of its flows and information processing has intensified.

The role and importance of international organizations (UN, IMF, World Bank, etc.) in the regulation of the world order of procedures and processes, non-governmental non-profit organizations, transnational corporations is increasing. Global markets and systems of their cross-border regulation are being formed.

A multinational elite united by common interests rules the world economy.

A bipolar, multipolar, and unipolar world, a war between the worldviews of capitalism and socialism and the ideologies of fascism, totalitarianism, etc. gave way to the global struggle for technology and information, dominance in artificial intelligence, neurotechnology, communications, and digital technologies.

As a result, traditional international relations between individual states have transformed into a world political process - a qualitatively new structure of interaction. The classical approaches to the theory of international relations fade to the theories of transnationalism, integration, neorealism, and structuralism, reflecting the realities of the transformation of the modern world into integrity, into a system that ensures the transition from chaos to a certain order, self-government. The number of subjects of the international political process is much wider than the international relations of individual states, and their activities may not be regulated. The world political process involves not only states and their interaction, but also relations with international associations (UN), regional and interstate associations (Council of Europe, Organization of American States OAS, Organization for Security and Cooperation in Europe OSCE, Commonwealth of Independent States, Association of Countries Southeast Asia, etc.), organizations and institutions, international non-governmental associations and organizations, international processes and the system of transnational politics. The process is considered in terms of the relationship of the political space to the economy, the level of development of scientific and technological progress, politics, vertical and horizontal ties. It forms the global political system, the structure of the global community (unions, coalitions), global development, and regulation institutions.

Within this process, international financial and economic organizations, such as the International Monetary Fund (IMF), the International Bank for Reconstruction and Development (IBRD), the International Chamber of Commerce (MPT), the World Trade Organization (WTO), transnational corporations are global in terms of the level and nature of their impact on global relations. These organizations contribute to the political settlement of financial relations in both the world and international trade, and transnational corporations largely determine the political strategy in world economic development and cooperation.

These transformations in international relations have caused changes in the financial mechanisms for their implementation. The financial and investment mechanisms of industrial policy, as well as financial instruments for regulating supply and demand, aimed at changing the structure of the market, are replaced during globalization with financial engineering instruments that level cross-border risks and provide insurance and long-term planning of financial flows. Along with traditional financing, investing, and lending, financial engineering and stock market tools, such as options, forwards, futures, junk bonds, leveraged buybacks, arbitrage operations, "bridge" and "project" financing, consortia-based financing, private placement, swaps, financing through vertically integrated structures, etc., are used [Marshall John F. et al, 1998: p.101, p.584, p.593]. Both transnational corporations and the 
banking sector and the institutional sphere (insurance, investment funds, etc.) actively use such instruments. The mechanism of action of these instruments is based on a change in the structure of risks in global markets, optimization of strategic marketing to increase liquidity, and also serves as an effective replacement based on the action of market mechanisms, government price subsidies and concessional lending. They made it possible to unify international financial instruments and form global standards of financial behavior. Their servicing infrastructure occurs - international financial corporations operating in global markets. Digital technologies in the financial sector are becoming widespread in data processing in the banking and public sectors. The role of banks is still great. The role of bank credit history for ordinary citizens is growing. The systems of world ratings, monitoring at the level of international organizations are developing, the importance of information and analytical resources of the world level is increasing. During this period, global currencies cryptocurrencies and blockchains - began to appear.

In the era of globalization, world financial wars appear as special technologies for the implementation of international relations at the level of individual states, including with the use of international organizations. They represent the development and implementation of international financial policy and operational strategies through the use of sanctions in international trade, the reform of the World Bank, the conclusion of international agreements on cancellation of the debt of individual countries, meetings of the G7 finance ministers, international information wars, inside information, formation of coalitions to freeze financial flows of certain organizations, restriction of access to financing at the international and state level and in the banking sector, financial recovery of individual countries from the budget system to the institutional sphere (banking, insurance, etc. sectors), control of the development of new currencies, the organization of humanitarian aid and the financing of educational projects, the formation of international funds for non-governmental organizations, the expansion of the activities of transnational corporations, the organization of processes and actions in the world outside under the guise of fighting any global threats, while pursuing other economic goals, etc. [John B. Taylor, 2007]. National security policy intersects with global finance.

Global trends also indicate the first doubts about the effects of globalization for solving world economic problems of production and consumption and ensuring the national security of individual states. [Stepnov I., 2019]. For some states, its process further perpetuates international inequality.

Globalization and its corresponding financial instruments and technologies of international relations represent an attempt by capitalism to expand consumption not through traditional wars and military conflicts, but through the conquest of new markets and destabilization processes that change the structures of supply and demand in the global market. In this regard, the importance of military superiority is decreasing.

The expanded consumption system formed by these processes due to the availability of new markets has its limits too. Markets are divided and saturated with goods (the gap between the levels of development of states is large and is unlikely to ensure dramatic structural changes in them, competition for world domination between high-tech powers, the rest fit into integration processes), there is a need to only regulate the minimum demand, maintain offer, and ensure reproduction, rather than to stimulate growth. The capitalist principles of the economy, the money of the traditional world financial and industrial capital cannot cope with the continuity of the process of expanding its volume and ensuring market regulation of supply and demand. This requires a search for qualitatively new ways of developing technologies, principles and forms of organization of society, social and political models.

Disappointed in globalization, many countries see the merging of markets to be not a chance for prosperity, but an ever-growing threat to national security. Not only the reverse processes of globalization begin - withdrawals from international agreements, the closure of 
domestic economies, the desire for strategic autonomies, the protection of their own producers, but also the processes of geopolitics and digital geopolitics are rapidly gaining momentum [D. Cave et al, 2019].

Digital geopolitics combines two opposing trends in international politics. On the one hand, it is based on the policy of ensuring the power of individual territories, while on the other, it includes the construction of decentralized transnational networks, consisting of the combined network resources of non-state structures and transnational companies, platforms, nodes, content and infrastructure on the other side of the politically established territorial formations. Both trends are not new, but often discussed separately from each other. While the fusion between these two trends is new, which manifested itself in the case of Huawei; it clearly showed the dimension associated with the provision of power for individual territories (the United States, China, the European Union) and public security, which increasingly forms the basis of digital geopolitics, and therefore requires our special attention. The EU, like Europe as a whole, is at risk of being stone-ground by superpowers, whose internal market is becoming the scene of a proxy technological war between the United States and China. The EU is fully aware of its economic and technological dependence on China. The central lines of conflict in relations between the EU and China have become issues of industrial policy, market access, and data protection. However, the EU recently decided against excluding Chinese enterprises from its internal market. China has been linked to numerous cases of cyber espionage against European information and communication structures. Nevertheless, close cooperation in security policy with the United States, as well as NATO, can lead to economic imbalances.

These processes strengthen the current trends in the development of scientific and technological progress and the digital revolution.

Machines worked their way from learning and analysis to self-organization and organization. The role of algorithms (step-by-step decisions, procedures ensuring the availability of services or goods) in the economy and social life is growing. [Stepnov I., 2016]. Revolutions in Artificial Intelligence, cybernetics, neurotechnology, biotechnology are accelerating the reality of the emergence of "Cyborgs". Against the background of digital dependence and the unification and standardization of the thinking of the population, the differentiated accessibility of education, the destruction of individualism, all this aggravates the social problems of the uselessness of people in the economy. People are not still exploited as in capitalism, but are completely useless.

The development of a new generation of the Internet, $5 \mathrm{G}$ mobile communications, virtual reality, hallograms, digital technologies for organizing society increases the risk of a digital divide in the development of countries and the consolidation of inequality, accessibility and affordability of technologies and education.

Methods of manipulating people's consciousness are becoming more sophisticated, being no longer just marketing, but neurotechnology of a new level. The volume of information is increasing to the extent that an ordinary person cannot imagine he/she is being manipulated from another part of the planet.

Cybernetic threats to industry - methods and technologies for manipulating states are increasing.

The main thing is the struggle for technological leadership, technological sovereignty in artificial intelligence and neurotechnology.

Confidence in liberalism is falling against the backdrop of the digital revolution, neurotechnology, biotechnology, and artificial intelligence revolutions. A small elite can rule with a digital dictatorship using big data algorithms.

These trends in the level of development of scientific and technological progress and the digital revolution have affected international relations and indicate the formation of trends in the development of supervisory capitalism with elements of digital totalitarianism, the 
strengthening of the role of digital geopolitics and digital colonialism. Previously, empires siphoned off resources, processed them, and sent them back to the colonies, forcing private producers out of the markets. Now they do the same with data. Multinational companies are pumping out data, processing information, and creating advanced products to distribute them in colonies. The processes of formation of digital totalitarianism are observed. In the United States, there is digital surveillance capitalism - the surveillance of corporations and multinational companies for consumers. Earlier, American banks had formed a system of credit histories for the population and ratings for companies that determine the availability of certain services. Algorithms are now shaping people's choices using marketing and neurotechnology. China lives in state digital totalitarianism - in which the government establishes a people ranking system with an assessment of their every action. Since 2014, Social Credit of Trust - the Big Data system has been launched in China; it exercises total control over the private life of residents by 5 parameters and 24 indicators, determining the availability of services and opportunities, rewards and punishments [S. Hoffman, 2018]. Russia and Turkey use different forms of illiberal democracies, with elements of dictatorship.

In all digital systems, a person is the subject of continuous surveillance. The world economy, organization and redistribution of resources will increasingly depend on the choice of a person, which is up to algorithms.

The principles of polycentrism and polyhierarchy in international relations collapse, giving way to spontaneous processes and the strengthening role of subjective factors. The ruler of the world will be the one who gets a monopoly on artificial intelligence, neurotechnology, and digital technologies.

We shall consider the emerging spectrum of new financial instruments of international relations, the emerging digital totalitarianism, entailing fundamental changes in the field of finance.

Under digital totalitarianism, financial instruments will be differentiated according to the conveyor and process principle, serving the resource redistribution processes. There is no need to stimulate growth, as markets are divided, and thus regulation is minimal. There is a transformation of financial instruments from financial instruments for mobilizing resources and concentrating them on development priorities to the priorities of financial instruments and technologies for the allocation of resources and their redistribution in society. Previously, the functionality of finance was mainly aimed at servicing and ensuring coordination of the activities of participants in economic processes, now methods, tools and technologies of total financial control and monitoring, definitions by the parameters of access to resources and services, the role of assessing the actions of participants in economic processes is increasing.

The traditional banking model and money are expected to undergo significant transformations.

There is a transformation of money as a universal means of exchange and trust, as well as the traditional banking model as an institution for attracting and redistributing resources in the economy into electronic instruments-digital money (for example, Libra from Facebook, electronic wallets, etc.) and financial digital technology. Financial technology has become as complex as possible. In addition to the algorithms that serve them, ordinary people cannot figure them out without special training and education. The development of digital financial products has significant effects and attacks on the traditional banking model - a lot of small deposits and funds on accounts will leave the deposit insurance system, the base for deductions will decrease, the financial situation of banks will worsen, as these liabilities are the cheapest for banks. The cost of liabilities for banks is already growing. All this will lead to an increase in bankruptcies.

Escalation of fiscal and trade disputes worldwide and volatility of markets accelerated the development of cryptocurrencies (Ethereun, IOTA, XRP BNB, Bitcoin, Huobitoken, etc.) and electronic wallets, strengthened the position of digital corporations in the financial sector. 
Cryptocurrencies will break the established global infrastructure in terms of power and dominance of one country over another. Historically, the world's reserve currency has always been the one of some dominant superpower, be it ancient Athens or the United States (dollar) if we take the segment of world history from the end of World War II. With the development of cryptocurrencies, national currencies will gradually withdraw from transactions. The cryptocurrency will allow states to survive any attack from outside, and will provide protection from political changes for users. The need arises to deal with the regulation and control of cryptocurrencies, including at the global level.

Algorithms rule the world; therefore, process evaluation is inevitable. The role and significance of the ranking and assessment system, including at the global level, is growing. There are questions of a moral and ethical plan - how close can algorithms be allowed to a person, through the financial system, the system of public services, medicine, digital technologies.

Linking financial instruments to biometric systems and neurotechnologies will bring cardinal changes. Sberbank of Russia is already collecting customer biometrics. Based on the growing importance of financial control, assessments, ranking for people, this opens up a whole layer of social, ethical, and other issues.

The volumes of non-cash payments are increasing, while the cash turnover of funds is hampered. The opportunities for total control are increasing, which will change tax systems and entail global tax reforms.

We should also note the limiting factors of these processes:

1) the gap and differentiation of countries according to the level of technology development, socio-economic development;

2) the struggle between the elites of the traditional industrial and banking sector and the new digital financial sector;

3) history teaches - empires with their standardization and unification ultimately disintegrate as long as decisions are made by people, due to the ambitions and human will.

Perhaps, we will soon face with new world digital financial wars, new technological battles for world domination, or for the preservation of our identity.

\section{Conclusion}

The article presents trends in the development of financial mechanisms and instruments of international relations in the course of globalization and the digital revolution. The differentiation of countries by the level of technological and socio-economic development, activity and involvement in the global political process certainly determines the possibilities of using these instruments and the policy of participation in the world process. Most countries are still using financial instruments and technologies of international relations at the level of the industrial and agrarian revolutions - using factor financial mechanisms aimed at the formation of funds and their regulation, investment-stimulating the development of investments aimed at mobilizing and concentrating financial resources on development priorities, marketing, regulating supply and demand systems. The task is to choose whether to focus political action only on countering threats or on creating opportunities for the advancement of strategically significant goals in the context of foreign policy and security in digital technology policy in world relations. It is especially relevant for Russia to define its own foreign policy priorities and determine its place and role in world politics and the global political process in the era of the digital revolution. 


\section{References}

1. John F. Marshall, Vipul K. Bansal, Financial engineering: a complete guide to financial innovation, 784 (1998)

2. Yuval Noah Harari, Sapiens. A brief history of humankind, 512 (2011)

3. Yuval Noah Harari, 21 lessons for the XXI century, 416 (2019)

4. Danielle Cave, Samantha Hoffman, Alex Joske, Fergus Ryan, Elise Thomas, Report, Mapping China's Tech Giants (2019)

5. D. Easton, Framework for political analysis (1965)

6. John B. Taylor, Global Financial Warriors: The Untold Story of International Finance in the Post-9/11 Word, 352 (2007)

7. R.O. Keohane, J. S. Nye, Introduction, Transnational Relations and World Politics (1972)

8. Samantha Hoffman, Social credit: technology-enhanced authoritarian control with global consequences (2018)

9. UNCTAD 2019, Trade and development report, 201 (2019), https:/unctad.org/

10. UNCTAD 2019, Digital economy report, 194 (2019), https:/unctad.org/

11. I. Stepnov , J. Kovalchuk, E. Gorchakova, Studies on Russian Economic Development, 20(3), 346 (2019)

12. Igor Stepnov, Julia Kovalchuk, Indian Journal of Science \& Technology, 9(42) (2016) 